\title{
Systematic development of a Weighted Hierarchical Topic Model for Educational Needs of Patients with type 2 diabetes
}

Azadeh Kamel Ghalibaf ${ }^{1}$, Zahra Mazloum Khorasani², Mahdi Gholian-Aval ${ }^{3}$, Mahmood Tara ${ }^{4}$

${ }^{1} \mathrm{Ph} . \mathrm{D}$. Candidate in Medical Informatics, Students Research Committee, Department of Medical Informatics, Faculty of Medicine, Mashhad University of Medical Sciences, Mashhad, Iran

${ }^{2}$ Endocrinologist Specialist, Assistant Professor, Division of Endocrinology, Department of Internal Medicine, Faculty of Medicine, Ghaem Hospital, Mashhad University of Medical Sciences, Mashhad, Iran

${ }^{3}$ Ph.D. of Health Education and Promotion, Assistant Professor, Department of Health Education and Promotion, Faculty of Health Sciences, Social Determinants of Health Research Center, Mashhad University of Medical Sciences, Mashhad, Iran

${ }^{4}$ M.D., Ph.D. of Health Informatics, Assistant Professor, Department of Medical Informatics, Faculty of Medicine, Mashhad University of Medical Sciences, Mashhad, Iran

\section{Type of article: Original}

\begin{abstract}
Background: Patient education is recognized as the most important component of diabetes management. In order to develop an effective educational program, it is crucial to identify diabetic patients' information needs.

Objective: This study aimed to systematically develop a weighted hierarchical topic model for the educational needs of patients with type 2 diabetes, based on the evidence.

Methods: Three types of information sources (i.e. research papers, guidelines and patient education websites) were reviewed systematically. PubMed was searched in August 2018 to find the relevant research papers without any limitations on the date of publication, guidelines were searched through the international network of healthcare guidelines, and educational materials were searched through Google search engine. Identified topics from the eligible resources were classified using the content analysis method. To determine the level of importance for each topic, a weighting model was developed based on the frequency of each topic and the strength of the information sources that have referred to it.

Results: In total, 142 papers were retrieved from PubMed database of which 17 studies were included. Searches for guidelines and websites led to five clinical guidelines for diabetes and ten patient educational websites that met the eligibility criteria. Topics were extracted from the included resources and were categorized into 6 main classes: Treatment process, course of disease, diabetes through the life cycle, pathophysiology of diabetes, coping and support.

Conclusion: In this study, several information sources were investigated to identify educational topics for the diabetic patient, considering both patient's and healthcare professionals' perspectives. The model created in this study can be adapted to the needs of future studies.

Keywords: Patient Education, Model Development, Systematic Review, Type 2 Diabetes
\end{abstract}

Abbreviations / Acronyms:

AMA: American Medical Association; CPG: Clinical Practice Guidelines; DM: Diabetes Mellitus; IOM: Institute of Medicine; T2DML: Type 2 Diabetes Mellitus

\section{Introduction}

Diabetes Mellitus (DM) is a highly prevalent chronic disorder which is growing rapidly in Iran and across the world (1). Diabetes can lead to some severe conditions such as cardiovascular diseases, blindness, renal failure and lower

\section{Corresponding author:}

Assistant Professor Dr. Mahmood Tara, Department of Medical Informatics, Faculty of Medicine, Mashhad University of Medical Sciences, Mashhad, Iran. Tel: +98.9158061511, Email: Taram@mums.ac.ir

Received: September 28, 2018, Accepted: February 20, 2019, Published: June 2019

iThenticate screening: February 28, 2019, English editing: March 18, 2019, Quality control: March 26, 2019

This article has been reviewed / commented by five experts

Funding / research project approval: Mashhad University of Medical Sciences (Ref: 950392)

(C) 2019 The Authors. This is an open access article under the terms of the Creative Commons Attribution-NonCommercialNoDerivs License, which permits use and distribution in any medium, provided the original work is properly cited, the use is non-commercial and no modifications or adaptations are made. 
limb amputations. All of which have given cause for diabetes management to be of great importance, both for the patients and healthcare services. However, there are several studies that demonstrated that the adherence to self-care practices is low in diabetic patients (2-4). According to a study done by Al Sayah and colleagues, it was revealed that the main reason for patients' non-compliance with self-care activities was unintentional issues such as lack of knowledge and skill barriers (5). Diabetes education is acknowledged as the cornerstone of care and has long been recognized as playing a vital role in assisting patients in managing their disease, but evidence has shown that more than half of the patients (76\%) had low to average information about their self-care (6).

In recent years, programs to educate people about self-management have become the focus of attention among healthcare professionals and are advocated for people with type 2 diabetes as a means to acquire the skills necessary for active responsibility in the day to day self-management of their condition. The American Diabetes Association states that self-management education should be offered from the point of diagnosis (7). The importance of education was also recognized by the patients. Some studies have shown that people with DM communicate considerable need for information, substantially more than people with cancer or cardiovascular diseases $(8,9)$. Due to the importance of education for diabetic patients, most of the clinical guidelines have addressed principals and strategies for developing educational plans for people with diabetes, and indeed, in some cases, specific guidelines have been dedicated to this purpose (10-13). In the traditional approach, healthcare professionals were responsible for patient education. However, in a study by Heisler and colleagues, it was found that despite the high acceptance of patients, constraints such as physician's limited time, lack of accessibility, use of technical terms and patients' forgetfulness, have made this approach impractical (14). Meanwhile, patient education material appeared to support and compliment physicians' recommendations. In order to design material that is effective and educational, it should be intelligible, evidence-based and consistent with patients' needs and conditions. Recent studies have demonstrated that presentation of educational information that is tailored to the patients' needs and health conditions is more effective $(15,16)$. When people find information relevant to their condition, they are more likely to read it carefully and act upon it. Due to the variety of complications associated with diabetes the information needs of the patients are diverse, which highlights the necessity of developing a structured model to present a precise view of the domain. Although diabetes is one of the largest public health issues, there is a considerable lack of studies addressing the information needs of patients, compared with other chronic diseases (17). Among the few studies conducted on diabetic patients' information needs, most were qualitative with a limited number of participants, which rendered the findings non generalizable $(8,9,18,19)$. In this study, the term "information wants" was used to refer to the patients' needs of information as they have perceived, and the term "information needs" was used to refer to the physician's view of what information is necessary to provide to the patients. This study aimed to design a weighted topic model for the information needs of diabetic patients, using a systematic review approach.

\section{Material and Methods}

The study was designed in five phases: identifying research questions, identifying search resources, selection criteria, data extraction and data analysis. Each phase consists of three sections corresponded to each of the three information sources, i.e. papers, diabetes guidelines and educational web sites. In the following, each phase has been described in detail.

\subsection{Phase 1: Identifying Research Question}

The specific questions that we aimed to answer in this study were, "What are the information topics for patients with type 2 diabetes, from the perspectives of healthcare providers and patients? And what is the degree of importance for each topic?"

\subsection{Phase 2: Identifying Search Resources}

Three distinct strategies were developed to systematically search each of the three categories of information sources, i.e. papers, guidelines and educational web sites. The purpose of reviewing research papers was to identify educational needs as perceived by diabetic patients. Meanwhile, patient education web sites and clinical guidelines were explored to identify perspectives from the other side, i.e. healthcare professionals. Findings from these two stakeholders were combined to form a comprehensive overview of the educational topics for diabetic patients.

2.2.1. Research design and search strategy

The search was carried out on August 22, 2018, using PubMed database, based on four main concepts: "Need", "Information", Diabetes" and "Patient" with keywords given in Table 1. The query was restricted to search only in the title of the articles.

\subsubsection{Guidelines}

The diabetes guidelines were searched through a specific library for clinical practice guidelines, called Guidelines International Network (20). This database includes over 6000 clinical guidelines from 93 organizations and 46 
countries, which facilitates the search of clinical guidelines (21). To retrieve diabetes guidelines, the term "Diabetes Type 2" was searched through the home page's search bar. Duplicates were removed from the search results and the rest were retained for further screening.

\subsubsection{Patient Education Websites}

The process of searching for educational websites was broken down into two steps. First, a Google search was conducted to identify the relevant websites for diabetic patients. Next, each of the eligible websites were 'handsearched' for potentially relevant educational contents (e.g. web pages, documents). The targeted web searches took place on April 13, 2018. On-line information lacks standard indexing and controlled vocabulary, which made the systematic search of websites challenging (22). Although the Cochrane Handbook for Systematic Reviews recommended incorporating grey literature, it provides limited guidance (23). To increase the sensitivity of search and to avoid the risk of overlooking relevant sources, several complementary search strategies were developed, containing multiple combinations of search terms from Table 1. For the case of this study, five unique search strategies were developed, as shown in Box 1, and implemented on Google search engine. The first page of each search's hits (representing 10 results) were reviewed, using the title and short text attached. The Potentially relevant websites were later entered into an Excel spreadsheet to screen the titles and further scanning content of the retained ones.

Table 1. Search terms used in the first phase of the study

\begin{tabular}{|l|l|}
\hline Concept & Keywords \\
\hline Need & $\begin{array}{l}\text { Need, wish, desire, preference, request, seek, talk, provision, perception, expectation, interest, } \\
\text { question, ask, search, demand, call, require }\end{array}$ \\
\hline Information & Information, knowledge, awareness, self-care, self-management, education, support \\
\hline Diabetes & Diabetes, Type 2 diabetes, diabetes mellitus type 2, diabetic, T2DM \\
\hline Patients & Patient, people \\
\hline
\end{tabular}

Box 1. Queries for Google search engine

\begin{tabular}{|l|}
\hline Diabetes AND Patient Education Materials OR Resources \\
\hline Diabetes AND Self-care OR Self-management Education \\
\hline Diabetic Patient Self care \\
\hline Diabetic Patient Self-management Brochure OR Handout OR Pamphlet \\
\hline Patient Education Materials AND Diabetes \\
\hline
\end{tabular}

\subsection{Phase 3: Inclusion and exclusion criteria}

\subsubsection{Research papers}

Studies that analyzed self-reported information needs of people with diabetes type 2 as a primary or secondary research aim were included. Information needs are defined as "recognition that patients' knowledge is inadequate to satisfy a goal, within the context/situation that they find themselves at a specific point in the time" (24). Original qualitative, quantitative or mixed-method studies were included. Studies reporting the information needs of relatives or healthcare professionals were excluded, as well as studies where relatives or healthcare professionals reported information needs of people with diabetes. Paper screening was performed in two stages, in the first stage papers were screened for titles and abstracts, followed by the second stage of scanning the full-text. The eligibility of articles for inclusion was assessed independently by two reviewers, and disagreements were resolved by a third reviewer.

\subsubsection{Guidelines}

According to the Institute of Medicine (IOM) (2011), clinical practice guidelines (CPGs) are systematically developed statements to assist practitioners and patient decisions about appropriate health care for specific clinical circumstances (25). Guideline selection criteria are divided into two categories: general criteria and specific criteria. General criteria are concerned with the credibility of guidelines in general, regardless of the specific requirements of this study, while in specific criteria, the special requirements of this study are considered. The general criteria to choose a guideline include:

1- The candidate document should explicitly identify itself as a "guideline", or "consensus"

2- Guidelines that were produced under the support of a health professional association or society, public or private organization, healthcare organization, or government agency.

3- Guidelines that were published in English from January 01, 2006 onwards.

4- When more than one set of guidelines were produced by the same working groups, only the most recently issued were considered 
The specific criteria for the selection of diabetes guidelines are as follows:

1-Only diabetes-specific guidelines were considered for inclusion, guidelines on cardiovascular diseases, blood pressure, and other diabetes related conditions were excluded;

2-Guidelines that include recommendations, strategies or information about the educational needs of diabetics.

3-Guidelines that are devoted to a specific subgroup of diabetic patients were excluded.

Guidelines in which the full text were not available and national guidelines that were adapted from one or more of the included guidelines were excluded from the study. The process of screening was conducted in two phases. In the first phase, titles and the table of content were screened, and then the full-text of potentially relevant guidelines were studied.

\subsubsection{Patient Education Websites}

The Internet has now become an important source of health information, but due to freedom of information, unqualified sources are able to create websites that offer expert advice. To ensure the quality and reliability of the included websites, a set of selection criteria were defined using the American Medical Association (AMA) principles (26):

1- Websites should be authored by medical professionals or policed by a governing body. Information ownership should be clearly indicated on the home page.

2- The main objective of the website should be to provide healthcare information not to sell products or provide healthcare services.

3- Funding or other sponsorship for any specific content should be clearly indicated. Advertising acknowledged should clearly differentiated from the site's content.

4- The information content should be up to date (not older than 5 years). The date that content is posted, revised, and updated should be clearly indicated.

5- The references of each topic should be clearly specified.

Each of the retrieved websites were evaluated against these criteria, and if all criteria were satisfied, the web content would be analyzed.

\subsection{Phase 4: Data Extraction}

In this phase, the included resources were studied in full-text and information was extracted. A data extraction form was developed and pilot tested by two authors on a random sample of included resources. Data extraction was carried out in two parts: The general data and the study's specific data; The general information extracted from papers included the author's name, publication year, study design, sample size and the study objective, meanwhile, for educational websites, the webpage title, and URL were extracted. For all three types of information sources (e.g. papers, guidelines and educational websites), the specific data include topics that were recommended to provide to diabetic patients.

\subsection{Phase 5: Data analysis and report}

Since the data that was extracted in the previous stage were of qualitative type, the content analysis method was used to identify the main themes. Content analysis is a systematic method to organize and describe qualitative data (27). Data coding is the first stage to categorizing the topics. We followed the directed approach for data coding, which uses the existing structure theory as a basis for coding and classification of data. For the case of this study, the existing source for coding was the topics recommended in a guideline which is dedicated to diabetic patients' selfcare education (10), and was introduced by the American Association of Diabetes Educators. The coding guide contains an operational definition for each category. The coding process was performed independently by two individuals and the reliability was calculated by Kappa coefficient.

\subsection{Developing Weighting Model}

In this stage, topics have been assigned weights to specify their level of importance. The weighting model was based on two parameters: the frequency of the topic and the type of information source. The frequency specifies the number of resources that referred to a specific topic, and the type of information source can be one of the following three: scientific paper, guideline, and patient education websites. Grading the strength of information resources was based on the "5s" model (28) which is a pyramid of literature quality introduced by the University of Michigan (29). In this model, non-scientific sources such as experts' opinion, website contents, etc. constitute the lowest level (first), the original studies belonged to the study layer (second), and guidelines mapped to the summaries layer, which is fifth in the pyramid. So, the information sources were involved in the equation with the following coefficients: guidelines $=5$, articles $=2$ and educational products $=1$. The weight of each topic was calculated using the Equation 1 (Ti refers to the $\mathrm{i}$-th topic in the model):

Equation 1: Weight $\left(\mathrm{T}_{\mathrm{i}}\right)=\operatorname{Frq}\left(\mathrm{T}_{\mathrm{i}}\right.$.Papers $) \times 2+\operatorname{Frq}\left(\mathrm{T}_{\mathrm{i}}\right.$.Guidelines $) \times 5+\operatorname{Frq}\left(\mathrm{T}_{\mathrm{i}}\right.$.WebSites $) \times 1$ 


\section{Results}

A total of 142 papers were retrieved from PubMed database. While screening papers, it was found that a prior review article with similar research questions exists, that has reviewed 26 studies on informational needs of diabetic patients (30). The full-text of these 26 articles was studied considering the eligibility criteria of the present study. Since our focus was on type 2 diabetes, 14 papers were accepted for inclusion in the current study. Furthermore, a complementary search was conducted to cover studies published between July 2015 and August 2018, which resulted in three extra eligible papers. Overall, 17 papers were reviewed.

The search strategy to identify diabetes guidelines resulted in 58 retrievals, after scanning, five guidelines met the eligibility criteria. In the search for identifying relevant patient education websites, the first page of Google results from each of the five queries yielded 50 potentially relevant items for screening. Following the screening process and removing duplicates, 10 websites met all eligibility criteria and were included for further manual search. The Study flow diagram is shown in Figure 1, which depicts the three phases of the review, including the number of records screened and included in the final synthesis. The number of the excluded items in each phase along with the reason have been reported.

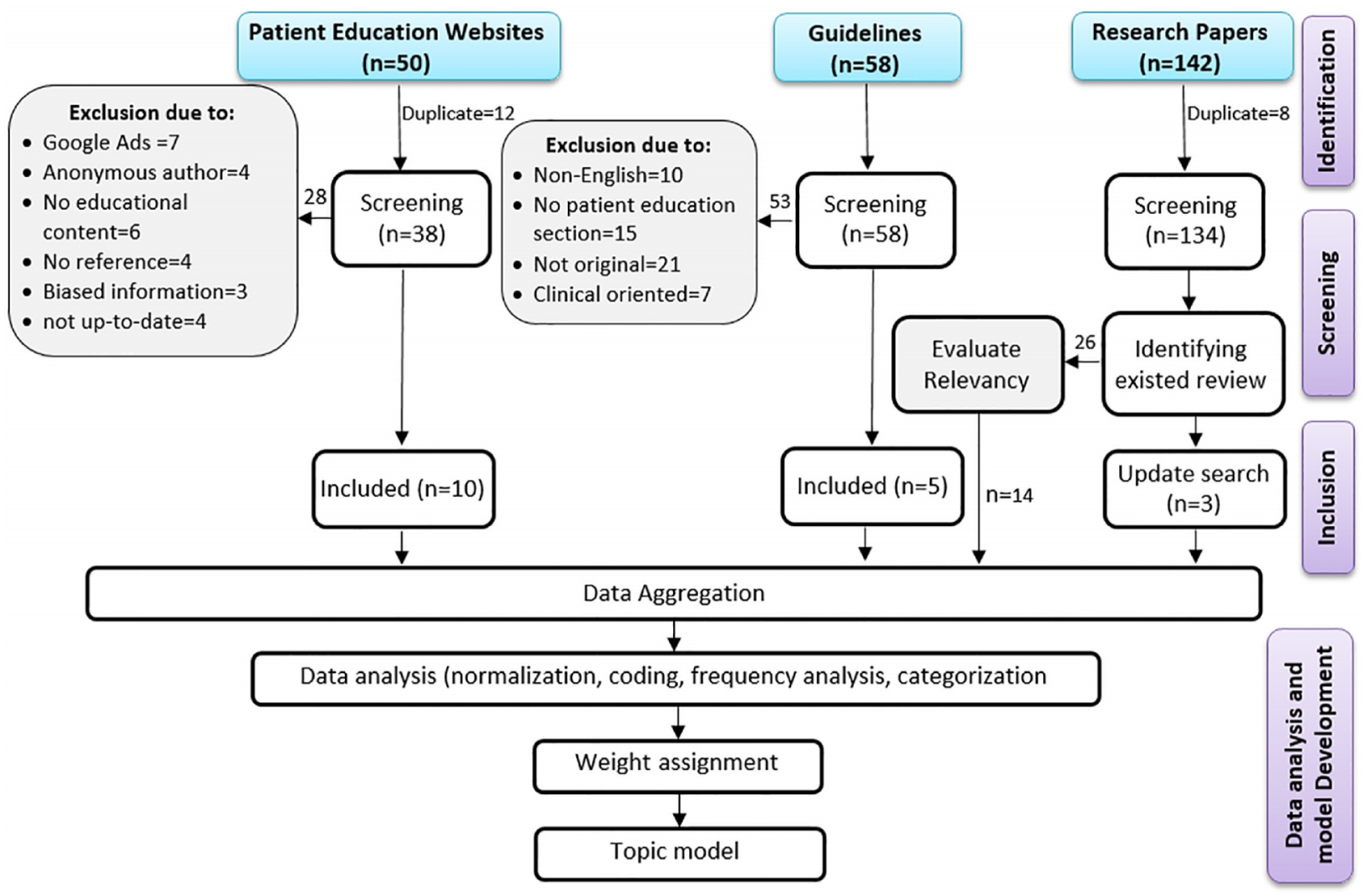

Figure 1. Search strategy and topic selection process

Considering the space limit of the paper and the large volume of data extraction tables, the detailed information extracted from each resource is grouped based on their information source. The extracted topics along with their references were collected in an Excel file. Terms that refer to the same concept were normalized to increase the consistency. Then, topics were coded and organized into six main classes, each representing one main aspect that diabetic patients deal with. Topics that are categorized under the same class are either complementary or interrelated. Table 2 shows the main classes and their definitions and is used as coding guide. In the final topic model, topics are categorized into six main classes, each may have up to three subclasses. Figure 2 presents a classification map that provides a visual overview of topics along with their weights. We have used XMind Version 3.2.1 to develop this map. 


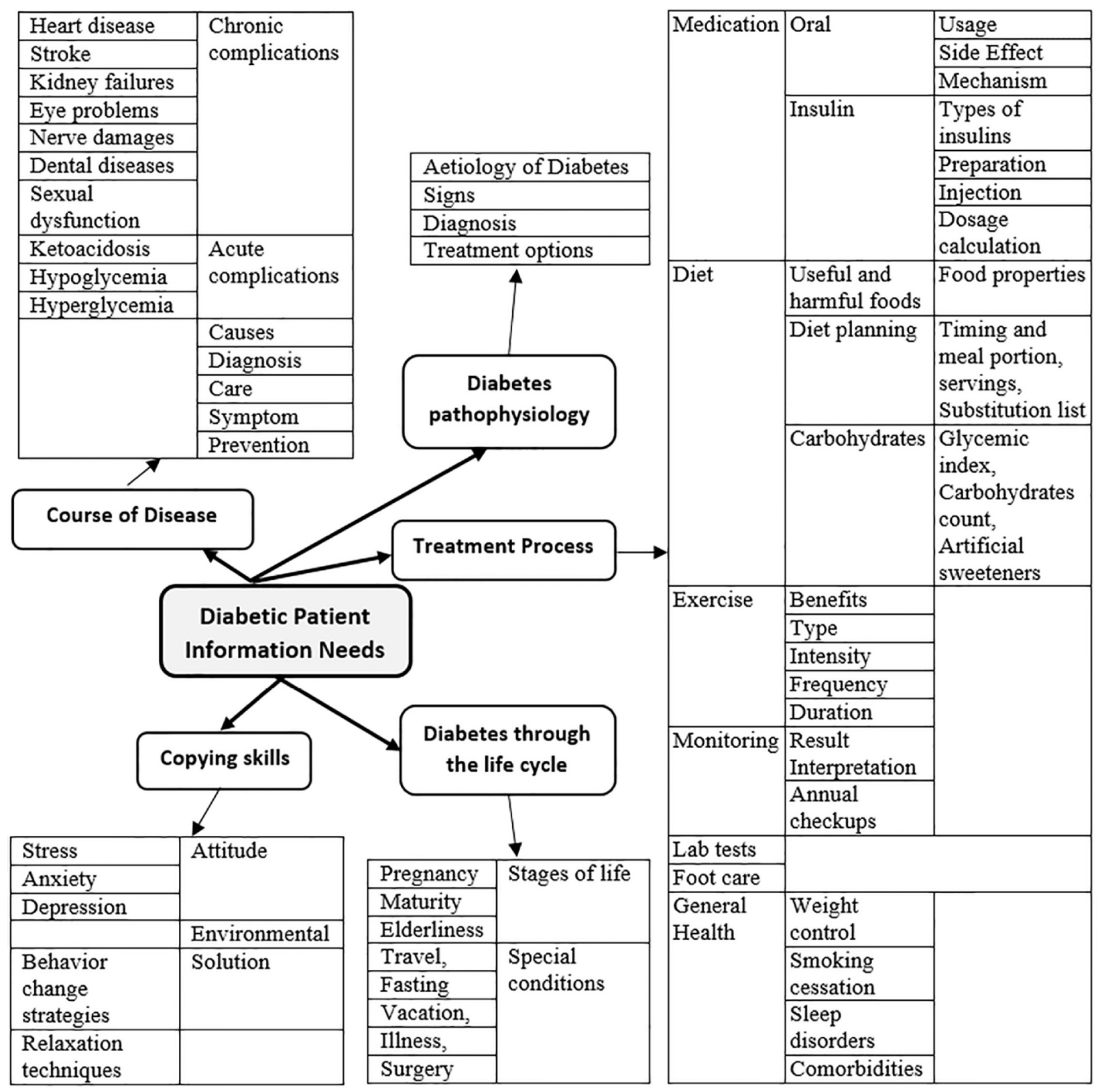

Figure 2. Concept map of educational topics for diabetic patients

Table 2. The coding guide to classify topics

\begin{tabular}{|l|l|}
\hline Classes & Definition \\
\hline Treatment process & $\begin{array}{l}\text { Information needs concerning administration or application of remedies to a patient, or } \\
\text { concerning diabetes self-management. }\end{array}$ \\
\hline Course of disease & $\begin{array}{l}\text { All information needs on topics related to the course of disease (progression through a } \\
\text { development or period of illness, symptoms, side effects). }\end{array}$ \\
\hline $\begin{array}{l}\text { Diabetes through the } \\
\text { life cycle }\end{array}$ & $\begin{array}{l}\text { Information needs related to topics that are part of different stages of the human life course } \\
\text { - traditionally, this includes childhood, adolescence, adulthood and old age; as well as } \\
\text { special conditions, situations and events. }\end{array}$ \\
\hline $\begin{array}{l}\text { Pathophysiology of } \\
\text { diabetes }\end{array}$ & $\begin{array}{l}\text { Diabetes-related information needs on topics that refer to the pathophysiology of diabetes } \\
\text { (e.g. impaired insulin secretion and increased insulin resistance). }\end{array}$ \\
\hline Coping Management & Coping skills related to stressful and critical conditions. \\
\hline Support & $\begin{array}{l}\text { Information needs related to support that which is defined as a person or thing that provides } \\
\text { aid or assistance in managing diabetes more efficiently. }\end{array}$ \\
\hline
\end{tabular}




\section{Discussion}

This is the first study on the development of a topic model for the information needs of patients in general and patients with diabetes in specific. Our approach to understanding the information needs of people with diabetes was to systematically explore and analyze multiple information sources, i.e. papers, guidelines and educational websites. The integration of information from several heterogeneous sources can provide a more comprehensive understanding of the domain. Topics were identified and aggregated from different sources and were organized in a hierarchical multi-layer structure where the upper levels represent the most general issues and the lower ones include more specific subjects. This helps the policy makers to develop more effective educational programs for diabetic patients.

Review of the evidence on information needs of patients with diabetes revealed that compared with other chronic diseases there is a considerable lack of studies in this field, despite diabetes being one of the largest public health issues (17). The content of information needs of diabetic patients, was similar to those found in people with other chronic diseases or cancer, such as "prognosis of disease", "diagnostic tests", "treatment", "self-care", and "emotional and psychological needs" (31). However, Duggan et al. found that people with diabetes have a higher need for information about drugs than people with cancer or cardiovascular diseases (9). Instruments for collecting information needs from individuals with diabetes have not been validated, methods and instruments should be further developed against a theoretical background and validated. Our findings revealed that the three themes ranked highest in providing information to diabetics include treatment, management, and prevention, which is in accordance with the findings of studies for cancer patients $(32,33)$. The knowledge presented about the information needs of diabetic patients through the proposed model can be used in targeted counselling and to strengthen the health literacy of patients.

The subjectivity of the data categorization process is a limitation in this study; however, we tried to increase the reliability by performing iterative pilot tests and expert panels throughout the process. Using only the PubMed database and filtering the search to the title of papers can be mentioned as the other limitations of this study, which was somewhat resolved by reviewing other information sources such as guidelines and web sites. Despite a significant amount of literature being systematically examined in this study, there is no claim that the obtained categories are definite or comprehensive. Factors associated with information needs, such as the effect of age groups, gender, types of diabetes, and changes in information needs during the course of the disease have not been studied in this research and can be investigated in future studies.

The primary strength of this study is its comprehensiveness in terms of search resources and the detailed and transparent description of the methodology. This study addressed educational needs of diabetic patients from the perspectives of both engaged stakeholders: the healthcare providers and the patients. Patients' viewpoints were investigated through research papers, and physicians' perspectives were sought out through the study of guidelines and educational websites, assuming that the content provided on diabetic patient education websites reflected the views of the specialists who compiled them.

The weighting model proposed in this study was a novel and innovative use of the hierarchy of evidence, where the level of each information source in the pyramid was regarded as its degree of importance in the weight calculation formula. Doing so, topics extracted from guidelines had the highest priority compared to papers and education materials. In this way, the effect of the type of information sources was considered in the calculation of the weight of topics. It is of worth to mention that the quality of information sources was determined at the level of general groups e.g. articles, guidelines, and educational websites. Intra-group rankings were not necessary since the design of all the included papers was the same (cross-sectional or surveys).

We believe that this study has contributions both for the field of diabetes patient education and systematic reviews. The search strategy we developed for identifying patient education content from websites is amenable to adaptation for a wide range of research questions in future studies, which suggests a feasible and seemingly robust method for applying systematic search strategies to identify web-based resources in the grey literature.

\section{Conclusions}

There is a limited number of studies analyzing information needs in diabetes, and there is a low number of studies investigating differences between subgroups of diabetes populations, including gender aspects or changes of information needs during the disease. This should be further investigated. The proposed model of information needs 
for diabetes patients can be used in targeted counselling and to strengthen the health literacy of people with diabetes. With the recent shift from physician-centered care to patient-centered care, such studies would be appreciated. It would be interesting to look for differences between people with diabetes and cancer or other chronic diseases in more detail.

\section{Acknowledgments:}

This study is the first author's PhD dissertation, which has been supported by a grant (Ref: 950392) from Mashhad University of Medical Sciences Research Council. The authors would like to thank Dr. Hamed Tabesh for his assistance with methodology design, and for the comments that greatly improved the manuscript.

\section{Conflict of Interest:}

There is no conflict of interest to be declared.

\section{Authors' contributions:}

All authors contributed to this project and article equally. All authors read and approved the final manuscript.

\section{References:}

1) Shafiee G, Nasli-Esfahani E, Bandarian F, Peimani M, Yazdizadeh B, Razi F, et al. Iran diabetes research roadmap (IDRR): the study protocol. J Diabetes Metab Disord. 2016; 15: 58. doi: 10.1186/s40200-0160277-z. PMID: 28018867, PMCID: PMC5160021.

2) García-Pérez LE, Alvarez M, Dilla T, Gil-Guillén V, Orozco-Beltrán D. Adherence to therapies in patients with type 2 diabetes. Diabetes Ther. 2013; 4(2): 175-94. doi: 10.1007/s13300-013-0034-y. PMID: 23990497, PMCID: PMC3889324.

3) Kirkman MS, Rowan-Martin MT, Levin R, Fonseca VA, Schmittdiel JA, Herman WH, et al. Determinants of adherence to diabetes medications: findings from a large pharmacy claims database. Diabetes Care. 2015; 38(4): 604-9. doi: 10.2337/dc14-2098. PMID: 25573883, PMCID: PMC4370331.

4) Mohebi S, Azadbakht L, Feizi A, Sharifirad G, Kargar M. Structural role of perceived benefits and barriers to self-care in patients with diabetes. J Educ Health Promot. 2013; 2: 37. doi: 10.4103/2277-9531.115831. PMID: 24083287, PMCID: PMC3778565.

5) Al Sayah F, Majumdar SR, Williams B, Robertson S, Johnson JA. Health literacy and health outcomes in diabetes: a systematic review. J Gen Intern Med. 2013; 28(3): 444-52. doi: 10.1007/s11606-012-2241-z. PMID: 23065575, PMCID: PMC3579965.

6) Shahrakivahed, A., et al., A study on the assessment of educational needs of diabetic patients. 2013.

7) Khunti K, Gray LJ, Skinner T, Carey ME, Realf K, Dallosso H, et al., Effectiveness of a diabetes education and self management programme (DESMOND) for people with newly diagnosed type 2 diabetes mellitus: three year follow-up of a cluster randomised controlled trial in primary care. BMJ. 2012; 344: e2333. doi: 10.1136/bmj.e2333. PMID: 22539172, PMCID: PMC3339877.

8) Beeney LJ, Bakry AA, Dunn SM. Patient psychological and information needs when the diagnosis is diabetes. Patient education and counseling. 1996; 29(1): 109-16. doi: 10.1016/0738-3991(96)00939-1.

9) Duggan C, Bates I. Medicine information needs of patients: the relationships between information needs, diagnosis and disease. Qual Saf Health Care. 2008; 17(2): 85-9. doi: 10.1136/qshc.2005.017590. PMID: 18385399.

10) Educators, A.A.o.D., Diabetes Education Curriculum: Guiding Patients to Successful Self-Management. Chicago, IL; American Association of Diabetes Educators, 2009.

11) Funnell MM, Brown TL, Childs BP, Haas LB, Hosey GM, Jensen B, et al. National standards for diabetes self-management education. Diabetes care. 2009; 32(S1): S87-94. doi: 10.2337/dc09-S087. PMID: 19118294, PMCID: PMC2613581.

12) Australia D. National Evidence Based Guideline for Patient Education in Type 2 Diabetes. Sydney: Diabetes Australia Guideline Development Consortium (DAGDC), 2009.

13) Powers MA, Bardsley J, Cypress M, Duker P, Funnell MM, Fischl AH, et al. Diabetes self-management education and support in type 2 diabetes. Diabetes Educ. 2017; 43(1): 40-53. doi: 10.1177/0145721716689694. PMID: 28118121.

14) Heisler M, Bouknight RR, Hayward RA, Smith DM, Kerr EA. The relative importance of physician communication, participatory decision making, and patient understanding in diabetes self - management. Journal of general internal medicine. 2002; 17(4): 243-52. doi: 10.1046/j.1525-1497.2002.10905.x. PMID: 11972720, PMCID: PMC1495033. 
15) Kreuter MW, Strecher VJ, Glassman B. One size does not fit all: the case for tailoring print materials. Annals of behavioral medicine. 1999; 21(4): 276. doi: 10.1007/BF02895958. PMID: 10721433.

16) Noar SM, Benac CN, Harris MS. Does tailoring matter? Meta-analytic review of tailored print health behavior change interventions. Psychological bulletin. 2007; 133(4): 673.

17) Diabetes, WHO. World Health Organization: Global report on diabetes. 2016. Available from: http://apps.who. int/iris/bitstream/10665/204871/1/9789241565257_eng.pdf.

18) Wilson V. Patient use of the internet for diabetes information. Nurs times. 2013; 109(23): 18-20. PMID: 23888634.

19) Whitford DL, Paul G, Smith SM. Patient generated "frequently asked questions": identifying informational needs in a RCT of peer support in type 2 diabetes. Primary care diabetes. 2013; 7(2): 103-9. doi: 10.1016/j.pcd.2013.01.006. PMID: 23428963.

20) Network GI. Guidelines International Network. 2002.

21) Qaseem A, Forland F, Macbeth F, Ollenschläger G, Phillips S, van der Wees P. Guidelines International Network: toward international standards for clinical practice guidelines. Annals of internal medicine. 2012; 156(7): 525-31. doi: 10.7326/0003-4819-156-7-201204030-00009. PMID: 22473437.

22) Alberani V, De Castro Pietrangeli P, Mazza AM. The use of grey literature in health sciences: a preliminary survey. Bull Med Libr Assoc. 1990; 78(4): 358-63. PMID: 2224298, PMCID: PMC225438.

23) Higgins J, Lasserson T, Chandler J, Tovey D, Churchill R. Methodological expectations of cochrane intervention reviews. London: Cochrane; 2016; 5.

24) Ormandy P. Defining information need in health-assimilating complex theories derived from information science. Health expectations; 2011; 14(1): 92-104. doi: 10.1111/j.1369-7625.2010.00598.x. PMID: 20550592, PMCID: PMC5060560.

25) Kredo T, Bernhardsson S, Machingaidze S, Young T, Louw Q, Ochodo E, et al. Guide to clinical practice guidelines: the current state of play. Int J Qual Health Care. 2016; 28(1): 122-8. doi: 10.1093/intqhe/mzv115. PMID: 26796486, PMCID: PMC4767049.

26) Winker MA, Flanagin A, Chi-Lum B, White J, Andrews K, Kennett RL, et al. Guidelines for medical and health information sites on the internet: principles governing AMA web sites. JAMA. 2000; 283(12): 16006. doi: 10.1001/jama.283.12.1600. PMID: 10735398 .

27) Downe - Wamboldt B. Content analysis: method, applications, and issues. Health care for women international. 1992; 13(3): 313-21.

28) Haynes B. Of studies, syntheses, synopses, summaries, and systems: the " $5 \mathrm{~S}$ " evolution of information services for evidence-based healthcare decisions. Evidence-based nursing. 2007; 10(1): 6-7. doi: 10.1136/ebn.10.1.6. PMID: 17218282.

29) Library University of Michigan. Integrated "5S" Levels of Organization of Evidence Pyramid. 2018. Available from: https://guides.lib.umich.edu/nursing/evidence.

30) Biernatzki L, Kuske S, Genz J, Ritschel M, Stephan A, Bächle C, et al. Information needs in people with diabetes mellitus: a systematic review. Syst Rev. 2018; 7(1): 27. doi: 10.1186/s13643-018-0690-0. PMID: 29444711, PMCID: PMC5813383.

31) Rutten LJ, Arora NK, Bakos AD, Aziz N, Rowland J. Information needs and sources of information among cancer patients: a systematic review of research (1980-2003). Patient Educ Couns. 2005; 57(3): 250-61. doi: 10.1016/j.pec.2004.06.006. PMID: 15893206.

32) Fletcher C, Flight I, Chapman J, Fennell K, Wilson C. The information needs of adult cancer survivors across the cancer continuum: a scoping review. Patient education and counseling. 2017; 100(3): $383-410$. doi: 10.1016/j.pec.2016.10.008. PMID: 27765377.

33) Leydon GM, Boulton M, Moynihan C, Jones A, Mossman J, Boudioni M, et al. Cancer patients' information needs and information seeking behaviour: in depth interview study. BMJ. 2000; 320(7239): 909-13. doi: 10.1136/bmj.320.7239.909. PMID: 10742000, PMCID: PMC27332.

34) Lamberts EJ, Bouvy ML, van Hulten RP. The role of the community pharmacist in fulfilling information needs of patients starting oral antidiabetics. Research in Social and Administrative Pharmacy. 2010; 6(4): 354-364. doi: 10.1016/j.sapharm.2009.10.002. PMID: 21111392.

35) Whetstone M. Adults Living with Type 2 Diabetes: Kept Personal Health Information Items as Expressions of Need. ProQuest LLC; 2013.

36) NICE. Type 2 diabetes in adults: management. National Institute for Care and Exellence. NICE. 2017.

37) Lee D, Armour C, Krass I. The development and evaluation of written medicines information for Type 2 diabetes. Health education research. 2007; 22(6): 918-30. doi: 10.1093/her/cym048. PMID: 17947249. 
38) Powers MA, Marrero DG. Diabetes Self-management Education and Support in Type 2 Diabetes. Diabetes Care. 2015; 38: 1372-82.

39) Frandsen KB, Kristensen JS. Diet and lifestyle in type 2 diabetes: the patient's perspective. Practical Diabetes International. 2002; 19(3): 77-80. doi: 10.1002/pdi.327.

40) Weymann N, Härter M, Dirmaier J. Information and decision support needs in patients with type 2 diabetes. Health informatics journal. 2016; 22(1): 46-59. doi: 10.1177/1460458214534090. PMID: 24916569.

41) Savage S, Dabkowski S, Dunning T. The education and information needs of young adults with type 2 diabetes: a qualitative study. Journal of Nursing and Healthcare of Chronic Illness. 2009; 1(4): 321-30. doi: 10.1111/j.1752-9824.2009.01035.x.

42) St Jean BL. Information Behavior of People Diagnosed with a Chronic Serious Health Condition: A Longitudinal Study. 2012.

43) Karimi Moonaghi H, Zary N, Masiello I. Exploring educational needs and design aspects of internetenabled patient education for persons with diabetes: a qualitative interview study. BMJ open. 2016; 6(10): e013282.

44) Federation Id. Living with Diabetes. 2017. Available from: https://www.idf.org.

45) Initiative, N.D.E. Patient Education. 2016. Available from: http://www.ndei.org/.

46) Association, T.A.D. Patient Education Materials- Type 2 Diabetes. 2017. Available from: https://www.diabetes.org.

47) UK, D. Know Diabetes, Fight Diabetes. 2017. Available from: https://www.diabetes.org.uk/.

48) Self-management, D. Diabetes self-management. 2017. Available from: https://www.diabetesselfmanagement.com/.

49) Company T.D.H. Diabetes Life. 2017. Available from: https://www.dlife.com.

50) Rodgers GP. National Diabetes Information Clearinghouse (NDIC). 2017. Available from: http://diabetes.niddk.nih.gov.

51) Association (GDEA). Gabric Diabetes Education Association (GDEA). 2017. Available from: http://www.gabric.ir/.

52) Goldman RE, Sanchez-Hernandez M, Ross-Degnan D, Piette JD, Trinacty CM, Simon SR. Developing an automated speech-recognition telephone diabetes intervention. International Journal for Quality in Health Care. 2008; 20(4): 264-70. doi: 10.1093/intqhe/mzn021. PMID: 18492706.

53) Wilkinson E, Randhawa G, Singh M. Quality improvements in diabetes care, how holistic have they been? International journal for equity in health. 2014; 13(1): 29.

54) Abadi. Education, prevention, control, and treatment of diabetes- Diabetes Educator Guidelines, Editor. The Ministry of Health and Medical Education. 1392

55) Cheng A. Canadian Diabetes Association 2013 clinical practice guidelines for the prevention and management of diabetes in Canada. Introduction. Canadian journal of diabetes. 2013; 37: S1-3. doi: 10.1016/j.jcjd.2013.01.009. PMID: 24070926.

56) Society I.D. Iranian Diabetes Society. 2017. Available from: http://ids.org.ir/.

57) Robertson JL, Akhtar S, Petrie JR, Brown FJ, Jones GC, Perry CG, et al. How do people with diabetes access information? Practical Diabetes International. 2005; 22(6): 207-10. doi: 10.1002/pdi.818.

58) Grobosch S, Kuske S, Linnenkamp U, Ernstmann N, Stephan A, Genz J, et al. What information needs do people with recently diagnosed diabetes mellitus have and what are the associated factors? A crosssectional study in Germany. BMJ open. 2018; 8(10): e017895. doi: 10.1136/bmjopen-2017-017895. PMID: 30385437, PMCID: PMC6252653.

59) McCorry NK, Hughes C, Spence D, Holmes VA, Harper R. Pregnancy planning and diabetes: a qualitative exploration of women's attitudes toward preconception care. J Midwifery Womens Health. 2012; 57(4): 396-402. doi: 10.1111/j.1542-2011.2011.00143.x. PMID: 22758361.

60) Peel E, Parry O, Douglas M, Lawton J. Diagnosis of type 2 diabetes: a qualitative analysis of patients' emotional reactions and views about information provision. Patient education and counseling. 2004; 53(3): 269-75. doi: 10.1016/j.pec.2003.07.010. PMID: 15186863.

61) Ravert RD, Hancock MD, Ingersoll GM. Online forum messages posted by adolescents with type 1 diabetes. Diabetes Educ. 2004; 30(5): 827-34. doi: 10.1177/014572170403000518. PMID: 15510534. 